\title{
Announcements
}

\section{Editorial: Stable Isotopes / Swiss Sojourn}

I am pleased to be writing this editorial at home in my Canadian office, yet I already sorely miss my colleagues and friends at the PAGES IPO, the beautiful city of Bern and the wonderful landscape of Switzerland. My fivemonth sabbatical sojourn as a PAGES visiting scientist was highly memorable and productive, and an ideal chance to network in the paleoscience community and to recharge my intellectual batteries. I warmly thank Keith, the PAGES SSC, and the entire PAGES staff for granting me this honour, and I heartily recommend that others take advantage of the same opportunity. Some may be aware of my activities as the leader of the PAGES ISOMAP initiative, dedicated to continental isotope paleoclimatology, and especially to the mapping and modelling of water isotope data from paleoprecipitation. For more information on the progress of this initiative, readers are directed to the ISOMAP link on the PAGES web site.

My more immediate responsibility as the guest editor of this Stable Isotopes issue of PAGES News was to solicit Science Highlights from workers engaged in research falling under the theme of ISOMAP. Out of an embarassment of riches, I selected eight contributions that span important aspects of the subject. The first three deal with investigations using individual continental isotopic archives, the next two with modelling of water isotope systematics at widely differing spatial and temporal scales, and the final three with ongoing multiproxy research programs in which stable isotopes play a leading role. Although necessarily providing only a glimpse of the depth and breadth of the subject, these reports clearly speak to the existence of significant opportunities for involvement and training of young researchers in a dynamic and expanding field of research. I sincerely hope they number among the readers of PAGES News.

Tom EDWards

Universitiy of Waterloo, Canada twdedwar@sciborg.uwaterloo.ca

\section{Paleoclimate, Global Change and the Future}

The PAGES synthesis project:

At this year's fall AGU PAGES will be presenting the results of our recently completed synthesis of the last decade of PAGES relevant research and seeking input for the future direction of the PAGES program.

Synthesis Book:

One of the results of the PAGES synthesis efforts is a new book Paleoclimate, Global Change and the Future due to appear in the IGBP synthesis series. The book, written by a large number of scientists from the PAGES community, will be on display, and available for purchase, at the Springer Verlag booth.

Special Session: PP12 Paleoclimate, Global Change and the Future:

Convenors: Keith Alverson, Ray Bradley and Tom Pedersen

This session will seek to draw together contributions from the full range of paleoenvironmental sciences including continental, marine and ice archives as well as the modeling community. Focus will be achieved by concentrating on those aspects of past environmental change over the past millennium, the Holocene, and Glacial/Interglacial timescales with direct relevance to future societal concerns associated with anthropogenic climate change.

Town Meeting: PAGES will hold a town meeting and icebreaker to foster an open discussion on improving U.S. community engagement with the PAGES program and to allow the AGU community to help shape how PAGES will work in the future.

For further information on the AGU Fall Meeting Information see: http://www.agu.org/meetings/fm02top.html

\section{New on the PAGES Bookshelf}

\section{Tropical Glaciers}

Georg Kaser, Henry Arthur Osmaston

(C) Cambridge University Press

December 2001 | Hardback | 228 pages

ISBN: 0521633338

orders can be directed to:

directcustserve@cambridge.org

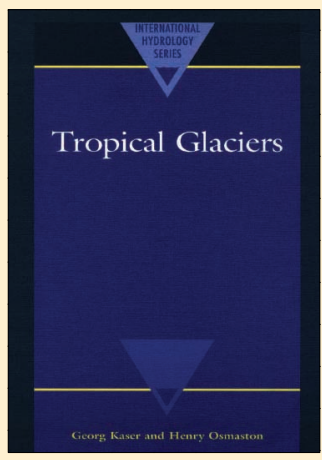

